\title{
Junior Middle School Students' Self-attribution in English Learning
}

\begin{abstract}
GAO Yuan-yuan
LI Yang

Qingdao University of Science and Technology,

Qingdao, China

Xi'an International Studies University,

Xi'an, China

The study explores the attribution characteristics of junior middle school English learners, hopefully to guide them to form a proper attribution style. Questionnaire method was adopted with 48 students from Chengyang No.17 as the subjects, the data from the questionnaire were analyzed with SPSS software and comparisons were made between female students and male students. Comparisons between female and male students showed that both female students and male students tend to avoid negative attribution styles, so their attributions are generally positive and desirable. As for differences, male students tend to attribute their English performance to external factors while female students to internal factors. English teachers may tailor the teaching method accordingly, so as to help students remold positive attribution styles, boost their learning motivation, and achieve desirable progress through attribution training.
\end{abstract}

Keywords: positive attribution, negative attribution, English learning, gender

\section{Introduction}

Attribution Theory focuses on how people explain the causes of the behaviors of others and themselves. Relevant studies started in 1960s in the field of psychology. American psychologist Hyde published The Psychology of Interpersonal Relationship (1958) which represented the birth of Attribution Theory. Bernard Weiner further proposed Motivation and Emotion Theory in 1970s. He pointed out that people tend to attribute their behavior results to six factors: ability, effort, luck, physical and psychological conditions, perceived difficulty of the task, and the environment. He also claimed that all these attributions can be classified based on three dimensions: locus of control, stability, and controllability (1972).

The three dimensions of Weiner's Attribution Theory can be summed up as follows:

Table 1

Weiner's Three-Dimensional Attribution Model

\begin{tabular}{|c|c|c|c|c|c|c|c|}
\hline \multirow{3}{*}{ Factors } & \multirow{3}{*}{ Dimensions } & \multicolumn{6}{|c|}{ Attribution dimensions } \\
\hline & & \multicolumn{2}{|c|}{ Locus of control } & \multicolumn{2}{|c|}{ Stability } & \multicolumn{2}{|c|}{ Controllability } \\
\hline & & External & Internal & Stable & Unstable & Controllable & Uncontrollable \\
\hline Ability & & & $\sqrt{ }$ & $\sqrt{ }$ & & & $\sqrt{ }$ \\
\hline Effort & & & $\sqrt{ }$ & & $\sqrt{ }$ & $\sqrt{ }$ & \\
\hline
\end{tabular}

GAO Yuan-yuan, master, English Department, Foreign Languages College, Qingdao University of Science and Technology. LI Yang, Institute for English Language Education, Xi'an International Studies University. 
(Table 1 continued)

\begin{tabular}{|c|c|c|c|c|c|c|}
\hline \multirow{3}{*}{ Dimensions } & \multicolumn{6}{|c|}{ Attribution dimensions } \\
\hline & \multicolumn{2}{|c|}{ Locus of control } & \multicolumn{2}{|c|}{ Stability } & \multicolumn{2}{|c|}{ Controllability } \\
\hline & External & Internal & Stable & Unstable & Controllable & Uncontrollable \\
\hline Task difficulty & $\sqrt{ }$ & & $\sqrt{ }$ & & & $\sqrt{ }$ \\
\hline Luck & $\sqrt{ }$ & & & $\sqrt{ }$ & & $\sqrt{ }$ \\
\hline Physical and psychological status & & $\sqrt{ }$ & & $\sqrt{ }$ & & $\sqrt{ }$ \\
\hline Environment & $\sqrt{ }$ & & & $\sqrt{ }$ & & $\sqrt{ }$ \\
\hline
\end{tabular}

In case of a positive event, people tend to attribute it to an internal and stable factor, i.e., I achieved a high score in Mathematics test because I am talented. When a bad result happens, they tend to make an external and unstable attribution, i.e., I lost the basketball game because of the bad weather.

Weiner also made a further conclusion: Attribution affects learners' emotion and future anticipation, which will directly influence their learning motivation and outcomes of the subsequent study. For example, if people refer success to such stable factors as good ability or low-difficulty task, they will be more likely to expect success in the same situations. But if people attribute success to such unstable factors as effort or good luck, they may express a lower expectation for future success. On the contrary, if people refer failure to stable factors like low ability or high-difficulty task, they will lose confidence and expect bad results again; when people attribute failure to unstable factors like poor effort and bad luck, they will enhance motivation and expect a future success.

So attribution theory is closely related to the concept of motivation, and attribution training will be likely to help students form positive attribution style, boost their confidence, arise their interest, and improve their performance in English learning. Furthermore, although studies have been carried out on the achievement motivation attribution in recent years, few of them focus on the English learning of students in junior middle school. Therefore, it benefits a lot to study junior middle school students' self-attribution in English learning. First, it could guide junior middle students to form proper achievement attribution and increase their learning motivation. Second, it may provide references for English teachers of junior middle school to adopt effective teaching techniques. At last, it can further verify the Attribution Theory and enrich its practical experience.

\section{Research Method}

\section{Questionnaire and Subjects}

This study adopted the comparative analysis by means of questionnaire survey. The questionnaire included 18 items, mainly designed based on Weiner's three-dimension model and verified by earlier experiments. In 2008, CHEN Wei-hong used this questionnaire to conduct a study on college students in Lishui University, China. In 2014, a postgraduate student from Xi'an International Studies University used it again to study the attribution characteristics of English learners of senior middle school. So the questionnaire is scientific and mature enough to be applied to the present study.

It is also worth mentioning that two adjustments were made to adapt to the participants. Firstly, two more items were added at the beginning to reflect the participants' English learning attitude and self-evaluation of English achievements. Secondly, the order of the items was intentionally readjusted to avoid the interference of similar topics. 
The following table clearly presents the relationship between the sixteen main items (from Item 3 to Item 18) and three dimensions of Weiner's theory.

Table 2

The Distribution of the 16 Items in the Questionnaire

\begin{tabular}{|c|c|c|c|c|c|c|c|}
\hline \multicolumn{4}{|c|}{ Internal factors } & \multicolumn{4}{|c|}{ External factors } \\
\hline \multicolumn{2}{|c|}{ Controllable } & \multicolumn{2}{|c|}{ Uncontrollable } & \multicolumn{2}{|c|}{ Controllable } & \multicolumn{2}{|c|}{ Uncontrollable } \\
\hline Stable & Unstable & Stable & Unstable & Stable & Unstable & Stable & Unstable \\
\hline $\begin{array}{ll}9 & 12 \\
\end{array}$ & $\begin{array}{ll}3 & 11 \\
\end{array}$ & $\begin{array}{ll}7 & 13\end{array}$ & $14 \quad 15$ & $\begin{array}{ll}16 & 18\end{array}$ & $\begin{array}{ll}6 & 17 \\
\end{array}$ & 58 & $\begin{array}{ll}4 & 10\end{array}$ \\
\hline
\end{tabular}

I9, I12, I3, I11, I7, I13, I14, and I15 all belong to internal causality. I9 on confidence and I12 on interest fall into controllable and stable attribution pattern. I3 on effort and I11 on study method fall into controllable and unstable attribution pattern. I7 on ability and I13 on physical condition fall into uncontrollable and stable pattern. I14 on emotion and I15 on expectation fall into uncontrollable and unstable pattern.

I16, I18, I6, I17, I5, I8, I4, and I10 belong to external causality. I16 and I18 on the social relations with classmates and teachers fall into controllable and stable attribution pattern. I6 and I17 on help from teachers and classmates fall into controllable and unstable attribution pattern. I5 on the test difficulty and I8 on the test environment fall into uncontrollable and stable attribution pattern. I4 on luck and I10 on evaluation system fall into uncontrollable and unstable attribution pattern.

The study was conducted at Chengyang No. 17 Junior Middle School, Qingdao, China, and totally 48 participants from three parallel classes were enrolled. They shared the same English teacher, Chinese being their primary language and English their second language. The subjects were equally selected between genders - half female students, half male students. Besides, familiar with the writer, the participants were all willing to assist with the survey.

The questionnaire was finished in October 2015. All the participants completed the questionnaire at the same time for 15 minutes. General instructions were given at the beginning and all the items were presented in Chinese so that participants could have an accurate understanding of the questionnaire. In order to ensure that the results were not affected by the worries of participants, they were allowed to answer the questionnaire anonymously. All the questionnaires were taken back on the spot and the effective return rate was $100 \%$.

\section{Analysis and Hypothesis}

Firstly, the standard for evaluation was designed as follow: Four choices (from A to D) were assigned scores as $\mathrm{A}+4$ points, $\mathrm{B}+3$ points, $\mathrm{C}+2$ points, and $\mathrm{D}+1$ points.

When all the questionnaires were completed, the data were collected and then analyzed with SPSS19. The average scores of male and female students for each item were calculated and compared.

According to Weiner's theory and the previous related research, the researchers hypothesized that in light of the psychological factors, female students are more emotionally vulnerable, while male students are more likely to be independent in the learning attribution. That means female students tend to attribute to external factors while male students to internal factors.

\section{Results and Analysis}

As Table3 shows, female and male students' choices were respectively counted and their average scores of each item were calculated. Then the Independent Sample T-Test was calculated with SPSS to determine the 
significance of difference between two groups in each item. The confidence interval is $5 \%$, so if the Sig. is below $5 \%$, that means there exists a distinct difference.

Table 3

Comparison of Attribution Distribution Between Female and Male Students

\begin{tabular}{|c|c|c|c|c|c|c|c|c|c|c|c|c|}
\hline \multirow{3}{*}{ Items } & \multirow{3}{*}{ Distribution } & \multicolumn{8}{|c|}{ Item choices } & \multirow{3}{*}{$\begin{array}{l}\text {-Female students' } \\
\text { - average scores }\end{array}$} & \multirow{3}{*}{$\begin{array}{l}\text { Male students' } \\
\text { average scores }\end{array}$} & \multirow{3}{*}{$\begin{array}{l}\text { Significance } \\
\text { (Sig.) }\end{array}$} \\
\hline & & \multicolumn{2}{|c|}{$\mathrm{A}$} & \multicolumn{2}{|r|}{ B } & \multicolumn{2}{|c|}{$\mathrm{C}$} & \multicolumn{2}{|c|}{$\mathrm{D}$} & & & \\
\hline & & $\mathrm{F}$ & $\mathrm{M}$ & $\mathrm{F}$ & $\mathrm{M}$ & $\mathrm{F}$ & $\mathrm{M}$ & $\mathrm{F}$ & $\mathrm{M}$ & & & \\
\hline I9 & & 7 & 16 & 10 & 7 & 6 & 1 & 1 & 0 & 2.96 & 3.63 & 0.003 \\
\hline $\mathrm{I} 12$ & & 9 & 10 & 10 & 8 & 4 & 2 & 1 & 4 & 3.13 & 3.00 & 0.662 \\
\hline I3 & & 4 & 4 & 9 & 12 & 5 & 5 & 6 & 3 & 2.46 & 2.71 & 0.385 \\
\hline I11 & & 15 & 13 & 7 & 4 & 1 & 3 & 1 & 4 & 3.50 & 3.08 & 0.156 \\
\hline I7 & & 4 & 2 & 8 & 6 & 7 & 5 & 5 & 11 & 2.46 & 1.96 & 0.100 \\
\hline $\mathrm{I} 13$ & & 3 & 4 & 9 & 8 & 7 & 10 & 5 & 2 & 2.42 & 2.58 & 0.537 \\
\hline $\mathrm{I} 14$ & & 1 & 5 & 5 & 6 & 6 & 6 & 12 & 7 & 1.79 & 2.38 & 0.058 \\
\hline $\mathrm{I} 15$ & & 4 & 8 & 13 & 8 & 6 & 5 & 1 & 6 & 2.83 & 2.88 & 0.023 \\
\hline I18 & & 2 & 12 & 17 & 7 & 4 & 4 & 1 & 3 & 2.83 & 3.21 & 0.123 \\
\hline I16 & & 1 & 5 & 3 & 3 & 14 & 12 & 6 & 4 & 1.96 & 2.38 & 0.113 \\
\hline I6 & & 2 & 10 & 8 & 7 & 10 & 6 & 4 & 1 & 2.33 & 3.08 & 0.006 \\
\hline I17 & & 0 & 12 & 5 & 7 & 12 & 4 & 7 & 1 & 1.92 & 3.25 & 0.000 \\
\hline I5 & & 4 & 5 & 5 & 13 & 9 & 5 & 6 & 1 & 2.29 & 2.92 & 0.023 \\
\hline I8 & & 2 & 1 & 3 & 9 & 8 & 9 & 11 & 5 & 1.83 & 2.25 & 0.118 \\
\hline I4 & & 2 & 4 & 6 & 16 & 11 & 4 & 1 & 0 & 2.21 & 3.00 & 0.001 \\
\hline I10 & & 6 & 3 & 2 & 3 & 6 & 9 & 10 & 9 & 2.17 & 2.00 & 0.614 \\
\hline
\end{tabular}

Notes. A to D refer to the four choices of items; $\mathrm{F}$ is for female students while $\mathrm{M}$ for male students.

\section{Similarities}

As Table 3 shows, the values of Sig. are all far above 5\% in I12, I3, I13, I18, I16, I15, I8, and I10, which indicates no significant difference exists in these items. Further analysis was made according to the average scores. As discussed in "Analysis and Hypothesis", the assigned scores for choices A to D are $+4,+3$, +2 , and +1 respectively, so the calculated median score is +2.5 . The results show that the average scores of I12, I18, and I15 are all over +2.5 . This indicates that both female and male students tend to attribute to such factors as interest, relation with teachers, and expectation respectively. Firstly, among these three factors, interest and expectation are internal while relation with teachers is external. According to Weiner's theory, if students attribute good English achievements to interest and expectation (internal and stable), they will enhance self-esteem and increase expectations for future success. Secondly, both I18 (relation with teachers) and I16 (relation with students) fall into the external and controllable attribution pattern. More students attach importance to the comments from teachers (I18), which indicates that participants are more likely to take teachers' encouragement as a motivating force. Finally, both female and male students impressively attribute their English achievements to study method (I11), an unstable and controllable factor, which indicates that they believe a suitable study method will contribute to a good performance. This is also a relatively positive attribution style.

What is more, both groups gain a relatively low score in I16, I8, I14, and I10. That is to say, neither female nor male students tend to attribute their English study to relations with classmates, study environments, emotion, or evaluation system. 


\section{Differences}

The attribution differences between female and male students are also significant. Table 3 shows that the values of Sig. in I9, I4, I5, I6, and I17 are less than 5\% and male students' mean scores of the five items are all higher than females'. Specifically, boys are more likely to attribute to external and uncontrollable factors of I4 (luck) and I5 (test difficulty), but neither factor is positive for English learning. According to Weiner's theory, attributing failure to bad luck and high test difficulty is a way of face saving and attributing success to good luck and low test difficulty is also not a proper way to boost confidence and maintain stability. What is more, luck and test difficulty are uncontrollable factors, which will result in helplessness in learning and lack of motives for success. Male students' high scores in I6 (help from teachers) and I17 (help from classmates) suggest that boys dependent more on the help from the teachers and other classmates (external, controllable, and stable). They show a high tendency to attribute their failure to in sufficient external help, which is also obviously not a proper attribution method.

While in I9, female students' average level of confidence is lower than male students'. As confidence belongs to the internal, stable and controllable factor, when female students attribute success to this factor, they will boost self-esteem and promote learning motivation.

Besides, female students' average scores in I7 and I11 are also higher than male students'. That means female students tend to believe that ability and study method play an important role in their English study. So girls are more willing to self-examine their study, adjust learning method and make more progress.

\section{Summary}

On the whole, both female students and male students tend to avoid negative attribution styles, such as external environment, evaluation system, and emotion, so their attributions are generally positive and desirable.

But the results also suggest that the average scores of male students are higher than female students, especially in the latter eight items. It indicates that male students are more inclined to attribute to external factors. When failing an English exam, they may complain of lacking help from others, high-difficulty task, or bad luck. That means male students are likely to shrink responsibility in their English study. It is probably because male students' physiological development is slower than female students at this stage and their psychological mechanism is not mature enough to make right attribution. As a result, junior middle school English teachers should help the male students to build internal and controllable attribution models so that they can make a better understanding of their own weakness and improve themselves. By contrast, female students tend to attribute to internal factors and are more independent than their male counterparts. Their attributions are more positive than male students'. On the other hand, they tend to show more lack of confidence in English study, so teachers can give them more encouragement and boost their confidence. Therefore, the researchers' hypothesis was not verified by the study.

What is more, as both female and male students in this study consider teachers' comments as an important attribution factor, it is significant for teachers to set up a positive image and give constructive comments to all students.

\section{Conclusion}

According to the study, generally junior middle school students have a positive attribution style, but some negative tendencies are also worth noticing. Hopefully, the following advice may help English teachers to 
guide their students to form a more positive attribution pattern in English learning.

First, English teachers must have a full understanding of Weiner's attribution theory and do more studies on students' attribution style. Only in this way can they guide students in accordance with their aptitude and flexibly apply the attribution strategy. Taking this study as an example, male students should be guided to attribute more to internal factors.

Second, a good teacher-student relationship is essential for improving teaching quality. As shown in this study, most students believe that the relations with teachers will have a big influence on their English performance. This requires teachers to set up a positive image and treat each student equally. Only when a positive and close relationship between teachers and students maintains, can the attribution guidance play the biggest role in the subsequent English study.

\section{References}

Dornyei, Z. (1994). Motivation and motivatingin the foreign language classroom. Modern Language Journal, 78, $273-284$.

FU，H．．． (2010). 成功与不成功英语学习者归因倾向学习分析 (Learning attribution analysis of successful and non-successful English learners). 基础英语教学, 12(1), 20-23.

Hyde, F. (1958). The psychology of interpersonal relationship. New York: Wiley.

LIN, Z. M. (1989). 维纳“归因理论”的原则和原因的结构 (Principle and structure of Weiner's attribution theory). 心理学动态, $1,1-8$.

QIN, X. Q. (2002). 大学生外语归因倾向及其对归因现象的理解 (College students' self-attribution in English learning and their explanation). 现代外语, 1, 71-78.

SU, A. J. (1994). 中小学生学习成败归因上的性别差异的调查研究 (Differences in learning attribution between male and female students in primary and middle schools). 现代中小学教育, 1, 43-45.

Weiner, B. (1972). Theories of motivation. Chicago: Rand McNally.

Weiner, B. (1980). Human motivation. New York: Holt, Rinehart \& Winston. 